\title{
Discussion: Quantitative evaluation of microstructure characteristics of cement-consolidated soil
}

\author{
Arya Assadi Langroudi \\ School of Civil Engineering, University of Birmingham, Birmingham, UK
}

\section{Discussion:}

Chen et al. presented the findings of four SEM image analyses and four unconfined compression tests on reconstituted stabilized clayey silt samples to study the influence of three admixtures on particle/pore size and strength of cement-stabilized organic-rich soils. They concluded that admixtures inhibit "any reaction between the organic matters" and cement. They also postulated that a 0.01 unit decrease in the 'fractal dimension' and a 3$8 \mu \mathrm{m}$ increase in a grain's diameter (20-30\% of the total population) upon addition of admixtures to the soil-cement confirms the "deficiency of cement in reinforcing the soft soil with high organic content and acceleration of the increase in the strength of the cementstabilized soils". Unfortunately Chen and his co-authors gave few or no details of their test material properties (void ratio, density, saturation ratio), test procedures (sample preparation, SEM sample preparation, SEM imaging process, SEM image analysis), and interpretations (fractal dimension derivation, and how the fractal dimension is an indication of stabilization efficiency). Could they, therefore, explain a number of less clear issues? The test material appears to contain $70 \%$ silt and $30 \%$ kaolinite-dominant clay at a natural water content of $60 \%$.

The specific gravity for such soil could be estimated as 2.65 , which results in an e.S $S_{r}$ of 1.59 . Hence, could the authors indicate the value of either saturation ratio $\left(S_{r}\right)$ or void ratio $(e)$, as at the maximum possible saturation ratio of 1.0, the 1.59 natural void ratio for saturated clayey silt appears atypical. According to the test method, clayey silt was dried, crumbled, and sieved through a $2.5 \mathrm{~mm}$ mesh, mixed with cement, mixed with water, and compacted to the initial $60 \%$ water content. Hence, can the authors report the void ratio after compaction that accommodated such remarkable water content? Results suggest that about $92 \%$ of particles in the reconstituted specimen are sized $2-10 \mu \mathrm{m}$. This size refers to the postcementation state, in which particles are well coagulated due to the cement hydration. Could 
the authors confirm if over $92 \%$ of the natural clayey silt's constituents were sized $<10 \mu m$ ? If so, the iconic size distribution deserves a good deal of formation study (i.e. how the present silt was formed from the source granitic rock).

With the SEM observations, could the authors explain how SEM was deemed an accurate means to measure the mean pore size and void ratio? What were the effects of drying (i.e. shrinkage of $30 \%$ clay fragment) on $<5 \mu \mathrm{m}$ pores, in light of the fact that the pronounced pore size was reported as of $<1 \mu \mathrm{m}$ ? How did the authors ensure that the pronounced $<1 \mu \mathrm{m}$ pores were not associated with the cement-salt crystal globules instead of the soil? In addition, how did the authors ensure that the dark spots on SEM images were not topographic depressions rather than pores; also how was it determined that the bright spots on SEM images were not electron beam-charged areas (i.e. one common artefact due to coating) rather than solids? Fractal dimension is fundamentally associated with the grain size distribution or the relative population of size ranges in a granular assembly (Mandelbrot 1983; Turcotte 1986). Microfabric however, refers to the arrangement by which grains are sorted (Mitchell 1976). Could the authors further explain how 'matrix' fabric possesses lesser degrees of fractal dimension than a 'dispersion' fabric? Furthermore, it appears from equation 1 that the fractal dimension shows no systematic dependence on the soil, as it is formulated as a factor of grid length and grid number. Could the authors clarify the control of soil in the formulation? Fractal dimension is generically defined for mono-mineral materials (Lu et al. 2003). However, this was by and large ignored in the present work. It would be particularly interesting to find out more about how the authors distinguished between the fractal dimension defined as used in the present study and the fractal dimension used in the classic literature (Brown et al. 1996; Hyslip and Vallejo 1997; Posadas et al. 2001; Wang et al. 2008).

\section{References:}

Brown GJ, Miles NJ, Jones TF (1996) A fractal description of the progeny of single impact single particle breakage. Miner Eng. 9:715-726

Hyslip JP, Vallejo LE (1997) Fractal analysis of the roughness and size distribution of granular materials. Eng Geol 48:231-244 
Lu P, Jefferson IF, Rosenbaum MS, Smalley IJ (2003) Fractal characteristics of loess formation: evidence from laboratory experiments. Eng Geol 69:287-293 Mandelbrot BB (1983) The fractal geometry of nature. Freeman, New York Mitchell JK (1976) Fundamentals of soil behaviour. Wiley, New York. Posadas AND, Gime'nez D, Bittelli M, Vaz CMP, Flury M (2001) Multifractal characterization of soil particle size distributions. Soil Sci Soc Am J 65:1361-1367 Turcotte DL (1986) Fractals and fragmentation. J Geophys Res Solid Earth 91:1921-1926 Wang D, Fu B, Zhao W, Hu H, Wang Y (2008) Multifractal characteristics of soil particle size distribution under different land use types on the Loess Plateau, China. Catena 72:29-36 